\title{
Modulation of Hippocampal and Amygdalar-Evoked Activity of Nucleus Accumbens Neurons by Dopamine: Cellular Mechanisms of Input Selection
}

\author{
Stan B. Floresco, ${ }^{1}$ Charles D. Blaha, ${ }^{2}$ Charles R. Yang, ${ }^{3}$ and Anthony G. Phillips ${ }^{1}$ \\ ${ }^{1}$ Department of Psychology, University of British Columbia Vancouver, British Columbia, Canada V6T 1Z4, ${ }^{2}$ Department \\ of Psychology, Macquarie University, Sydney, New South Wales, Australia 2109, and ${ }^{3} E l i$ Lilly Company, Neuroscience \\ Research, Lilly Corporate Center, Indianapolis, Indiana 46285-0510
}

Inputs from multiple sites in the telencephalon, including the hippocampus and basolateral amygdala (BLA), converge on neurons in the nucleus accumbens (NAc), and dopamine (DA) is believed to play an essential role in the amplification and gating of these different limbic inputs. The present study used extracellular single-unit recordings of NAc neurons in combination with chronoamperometric sampling of mesoaccumbens DA efflux to assess the importance of DA in the integration of different limbic inputs to the NAc. Tetanic stimulation of the fimbria potentiated hippocampal-evoked firing activity of NAc neurons and increased DA extracellular levels. Systemic administration of the $\mathrm{D}_{1}$ receptor antagonist $\mathrm{SCH} 33390$ or the NMDA receptor antagonist CPP abolished the potentiation of hippocampal-evoked activity and produced a $D_{2}$ receptormediated suppression of evoked firing. In neurons that received converging input from the hippocampus and BLA, fimbria tet- anus potentiated hippocampal-evoked firing activity and suppressed BLA-evoked activity in the same neurons. Both $D_{1}$ and NMDA receptors participated in the potentiation of fimbriaevoked activity, whereas the suppression of BLA-evoked activity was blocked by either $D_{1}$ receptor antagonism with SCH23390 or the adenosine $\mathrm{A}_{1}$ antagonist 8-cyclopentyl-1,2dimethylxanthine. Coincidental tetanus of both the fimbria and $B L A$ resulted in potentiation of both inputs, indicating that DA and adenosine-mediated suppression of BLA-evoked firing was activity-dependent. These data suggest that increases in mesoaccumbens DA efflux by hippocampal afferents to the NAc play a critical role in an input selection mechanism, which can ensure preferential responding to the information conveyed from the hippocampus to the ventral striatum.

Key words: nucleus accumbens; hippocampus; basolateral amygdala; dopamine; NMDA; adenosine; gating
Neural mechanisms for the selection of adaptive behaviors in response to constantly changing environmental conditions are essential for survival in all species. Different adaptive responses can be influenced by multiple memory systems involved in specific cognitive operations which in turn control specific patterns of behavior (Sherry and Schacter, 1987; Nadel, 1992; McDonald and White, 1993). It remains to be determined how the brain integrates inputs from different information-processing systems to produce complex sequences of behavior appropriate to different environmental stimuli. For example, in ambiguous situations when an organism must choose between a variety of response options, which cellular mechanisms enable one neural network to have preferential access to motor effector sites, while inhibiting other potentially competing circuits?

The nucleus accumbens (NAc) is well situated for the integration of inputs from separate neural networks such as the hippocampal formation, which computes spatial and contextual information, or the basolateral amygdala (BLA), which processes

Received Dec. 1, 2000; revised Jan. 22, 2001; accepted Jan. 24, 2001.

This work was supported by a grant from the Natural Science and Engineering Research Council of Canada to A.G.P. S.B.F. is a recipient of a Human Frontiers Science Organization postdoctoral fellowship. We thank Drs. J. K. Seamans, N. Gorelova, H. Moore, and A. West for helpful comments on this manuscript.

Correspondence should be addressed to Dr. Stan B. Floresco, Department of Neuroscience, University of Pittsburgh, 446 Crawford Hall, Pittsburgh, PA 15260. E-mail: floresco@brain.bns.pitt.edu.

Dr. Floresco's present address: Department of Neuroscience, University of Pittsburgh, 446 Crawford Hall, Pittsburgh, PA 15260.

Copyright (C) 2001 Society for Neuroscience $0270-6474 / 01 / 212851-10 \$ 15.00 / 0$ stimulus-reward associations (Eichenbaum, 1996; Robbins and Everitt, 1996). The NAc receives excitatory glutamatergic afferents from limbic regions such as the BLA, prefrontal cortex, and hippocampus (Groenewegen et al., 1991; Brog et al., 1993; Mogenson et al., 1993; Pennartz et al., 1994; Meredith and Totterdell, 1999) and in many instances, inputs from these anatomically and functionally distinct regions converge on the same medium spiny neurons (Callaway et al., 1991; O'Donnell and Grace, 1995; Mulder et al., 1998). The NAc also receives a dense projection from dopaminergic neurons in the ventral tegmental area (VTA) ( Nauta et al., 1978; Björklund and Lindvall, 1984; Voorn et al., 1986). Recent neurochemical studies have shown that glutamatergic limbic inputs from the hippocampus and BLA can also exert direct control over phasic increases in mesoaccumbens DA release, in addition to release mediated by bursting activity of VTA neurons (Chergui et al., 1994). Brief, higher-frequency ( $>5$ $\mathrm{Hz}$ ) electrical stimulation of the ventral hippocampus or the BLA produces robust and long-lasting increases in mesoaccumbens DA efflux, and these effects appear to be mediated in part by glutamate-dependent mechanisms localized within the NAc (Blaha et al., 1997; Floresco et al., 1998; Taepavarapruk et al., 2000).

The effects of DA on striatal neurons are complex and can either inhibit (Yang and Mogenson, 1984, 1986; White and Wang, 1986; Pennartz et al., 1991; Mogenson et al., 1993; Harvey and Lacey, 1997) or facilitate (Pennartz et al., 1991; Gonon and Sundstrom, 1996; Harvey and Lacey, 1997; Hernández-López et al., 1997; Cepeda and Levine, 1998) synaptic activity of medium spiny neurons evoked by excitatory glutamatergic afferents. Sim- 
ilarly, DA can also exert differential effects on synaptic plasticity of striatal neurons, promoting either long-term potentiation or depression of glutamate inputs to medium spiny neurons, as a function of specific experimental conditions. Bath application of DA promotes long-term depression, whereas similar applications of DA in absence of extracellular $\mathrm{Mg}^{2+}$, or pulsatile administration of DA coincidental with tetanic stimulation of corticostriatal afferents facilitates long-term potentiation (Wickens et al., 1996; Calabresi et al., 2000; Nicola et al., 2000). These opposing actions of DA suggest that mesoaccumbens DA may play an important role in the integration and gating of different limbic signals to the NAc, by amplifying one subset of inputs while concurrently inhibiting activation of medium spiny neurons evoked by other afferent projections (Oades, 1985; Mogenson et al., 1993; Pennartz et al., 1994; Ikemoto and Panksepp, 1999; Redgrave et al., 1999). Although this remains a distinct possibility, previous studies investigating the effects of DA have focused independently on either its suppressive or facilitatory effects. Differential modulation by DA of separate limbic inputs converging on the same neurons in the NAc has yet to be demonstrated. The present study used electrophysiological recordings from NAc neurons that responded to either hippocampal stimulation alone or both hippocampal and BLA stimulation to assess (1) the relation between evoked efflux of DA in the NAc measured by chronoamperommetry and post-tetanic potentiation of the hippocampal-NAc pathway, (2) the effect of this potentiation on subsequent activity evoked by stimulation of the BLA on neurons receiving convergent input, and (3) the involvement of specific DA, glutamate, and adenosine receptors in these forms of homosynaptic facilitation and heterosynaptic depression.

\section{MATERIALS AND METHODS}

Animals and surgical preparations. A total of 111 male hooded rats (Long-Evans, Charles River, St. Constant, Quebec, Canada) weighing 250-350 gm were used. Animals were housed in individual stainless steel cages at constant room temperature $\left(24^{\circ} \mathrm{C}, 60 \%\right.$ relative humidity) and maintained on a $12 \mathrm{hr}$ light/dark cycle (lights on at 7:00 A.M.). Food and water were available ad libitum.

Rats were anesthetized with urethane $(1.5 \mathrm{gm} / \mathrm{kg}$, i.p.) and mounted in a stereotaxic frame. Body temperature was maintained at $37^{\circ} \mathrm{C}$ with a temperature-controlled heating pad (American Hospital Supplies, McGraw Park, IL). Rats were implanted with concentric bipolar electrical stimulating electrodes (SNE-100; Rhodes Medical Company, Kopf) in the fimbria and the BLA. The stereotaxic coordinates were: flat skull, fimbria electrode $=$ anteroposterior (AP) $-1.3 \mathrm{~mm}$ (bregma), mediolateral (ML) $+1.6 \mathrm{~mm}$, dorsoventral (DV) $-4.0 \mathrm{~mm}$ (cortex); BLA electrode $=$ AP $-3.2 \mathrm{~mm}, \mathrm{ML}+5.0 \mathrm{~mm}, \mathrm{DV}-7.0 \mathrm{~mm}$.

In some rats, stearate-modified graphite paste electrochemical recording electrodes that permit in vivo measurement of changes in DA efflux without interference from other oxidizable compounds in brain extracellular fluid (Blaha and Phillips, 1996; cf. their references) were implanted stereotaxically into the NAc, ipsilateral to both stimulating electrodes (AP $+1.5, \mathrm{ML}-1.0$ at $15^{\circ}$ angle, $\mathrm{DV}-6.5 \mathrm{~mm}$ ). In these preparations, an $\mathrm{Ag}-\mathrm{AgC} 1$ reference and stainless steel auxiliary electrode combination was placed in contact with cortical tissue $4 \mathrm{~mm}$ posterior to bregma.

Extracellular recordings. Extracellular single-unit activity was recorded with glass microelectrodes (5-10 $\mathrm{M} \Omega$; filled with Fast Green dye and 0.5 M sodium acetate). Single-unit activity was filtered (bandpass 500-5000 $\mathrm{Hz}$ ), and individual action potentials from single units were separated from noise using a window discriminator and sampled on-line by a computer connected to a Data Translation DT 2821 analog-to-digital board interface. Peristimulus time histograms were constructed on-line. For rats that had electrochemical recording electrodes implanted in the NAc, the placement of the microelectrode was set to the same anterior plane as the electrochemical recording electrode $(\sim \mathrm{AP}+1.5)$, and was $0.9-1.3 \mathrm{~mm}$ lateral from the midline and $5.0-7.0 \mathrm{~mm}$ ventral from the top of the cortex. This medial region of the NAc exhibits the greatest proportion of neurons that receive converging input from both the hippocampus and the BLA (Mulder et al., 1998), as opposed to the NAc core, which has very few neurons that receive converging inputs (Finch, 1996). The arrangement of electrodes ensured that the glass microelectrode would be in close proximity to the electrochemical recording electrode. Microelectrodes were lowered slowly into the medial shell region of the NAc using a hydraulic microdrive. Cells that displayed a signal-to-noise ratio of $<3: 1$ were not included in the analysis. Likewise, cells that displayed spontaneous activity of $>5$ spikes/sec were also not used in the analysis.

Electrochemical recordings. Repetitive chronoamperometric measurements of oxidation current using an electrometer (Echempro, Vancouver, British Columbia, Canada) were made by applying a potential pulse from -0.15 to $+0.25 \mathrm{~V}$ versus $\mathrm{Ag}-\mathrm{AgCl}$ to the recording electrode for 1 $\mathrm{sec}$ at $30 \mathrm{sec}$ intervals and monitoring the oxidation current at the end of each $1 \mathrm{sec}$ pulse. The timing of the potential pulse was set so that it would occur $>300 \mathrm{msec}$ after electrical stimulation of either the fimbria or the BLA to ensure that the artifact produced by the pulse would not overlap with evoked activity of NAc neurons. Prestimulation baseline currents were normalized to zero current values with stimulated changes in the baseline signal presented as absolute changes (increases as positive and decreases as negative values) in DA oxidation current (for details, see Blaha et al., 1997).

Stimulation protocol. After the glass microelectrodes had been lowered to the dorsal border of the NAc, a cell-searching procedure began. In this procedure, alternating stimuli were delivered to the fimbria and the BLA $(1800 \mu \mathrm{A})$ at $750 \mathrm{msec}$ intervals, while the microelectrode was lowered incrementally through the NAc. Cathodal constant current pulses (0.2 msec duration) were delivered to the fimbria and BLA through an Iso-Flex optical isolator (A.M.P.I., Jerusalem, Israel) via a Master-8 programmable pulse generator (A.M.P.I.) using parameters noted below. Once a cell was detected, the position of the microelectrode was adjusted to maximize the spike amplitude relative to background noise. Neurons that responded only to fimbria stimulation or received converging input from both the hippocampus and the BLA, were identified by their robust excitatory response after fimbria stimulation alone or by response to both fimbria and BLA stimulation. Cells that did not exhibit a monosynaptic response component to fimbria stimulation (latency range 6-11 msec; Mulder et al., 1998) were not used in the data analysis.

Once a cell was isolated, stimulation currents were adjusted to approximately half-maximal stimulation intensity (range, 200-1900 $\mu \mathrm{A}$ ), so that $\sim 50$ action potentials were evoked in response to a train of 100 fimbria or BLA stimulations delivered at $2 \mathrm{~Hz}$ frequencies. Evoked spike probabilities were calculated by dividing the number of action potentials observed by the number of stimuli administered. Changes in spike probabilities were used as an index of changes in the influence that hippocampal and BLA inputs exert over NAc neuronal activity. For neurons that responded only to fimbria stimulation, trains of $2 \mathrm{~Hz}$ stimulation to the fimbria ( 100 pulses for $50 \mathrm{sec}$ ) were delivered every 3-5 min. Once stable levels of evoked-spiking activity were obtained $(<15 \%$ variation in spike probability over 5-10 min), one tetanic stimulation of the fimbria was administered (200 pulses at $20 \mathrm{~Hz}$ for $10 \mathrm{sec}$, suprathreshold intensity). Previous investigations in our laboratory have shown that this tetanus parameter produces a reliable and robust increase in DA efflux in the NAc (Blaha et al., 1997; Taepavarapruk et al., 2000). Two minutes after tetanus (assigned as time 0), trains of $2 \mathrm{~Hz}$ fimbria stimulation were applied (100 pulses for $50 \mathrm{sec}$ at the same current as before tetanus), and this was repeated at 5 min intervals for another 25 min. Data were normalized to the spike probability of the sample $2 \mathrm{~min}$ before tetanus, and the data were analyzed in terms of percent change in spike probability.

A similar stimulation protocol and analysis was used for NAc neurons that received converging limbic input. Once isolated, stimulation currents for both inputs were adjusted to $50 \%$ maximal responding at $2 \mathrm{~Hz}$ frequency. Stimulation by single pulses at $2 \mathrm{~Hz}(100$ pulses for $50 \mathrm{sec})$ was administered to the BLA followed by an identical train to the fimbria. After stable baseline spike probabilities, a tetanus was delivered to the fimbria (200 pulses, $20 \mathrm{~Hz}$ for $10 \mathrm{sec}$ ). After tetanic stimulation (time 0 ), trains of $2 \mathrm{~Hz}$ stimuli ( 100 pulses for $50 \mathrm{sec})$ were delivered to the BLA at time points $15 \mathrm{sec}, 2 \mathrm{~min}$, and every $5 \mathrm{~min}$ thereafter; identical trains were delivered to the fimbria at time points $1 \mathrm{~min}, 3 \mathrm{~min}$, and every $5 \mathrm{~min}$ after, to a maximum of $25 \mathrm{~min}$. No more than two tetani to the fimbria were administered per animal, and the interval between tetanic stimulations was at least $3 \mathrm{hr}$.

Pharmacological manipulations. To permit administration of pharma- 

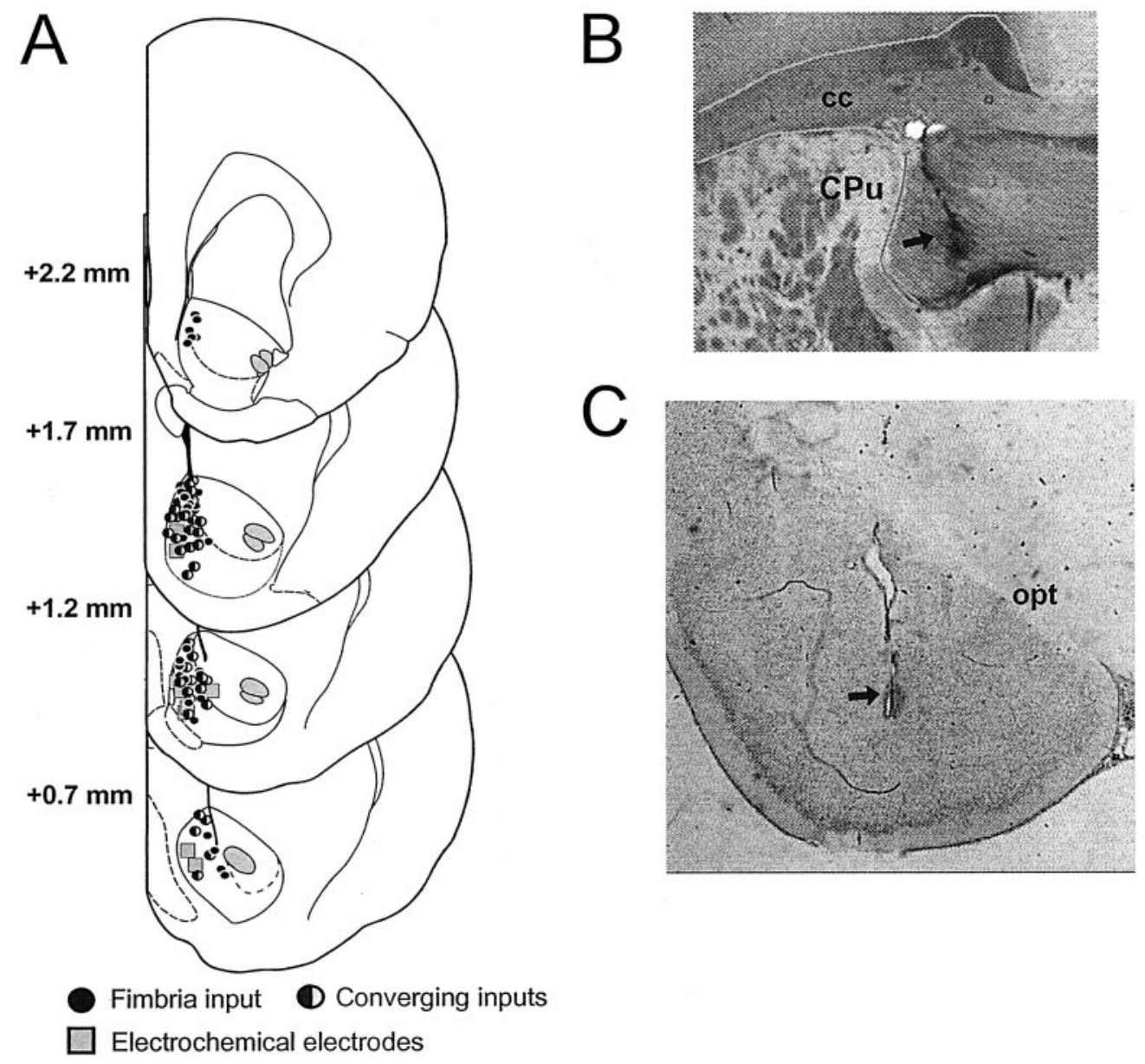

Figure 1. Histology. A, Schematic of coronal sections of the rat brain showing representative placements of electrochemical electrodes (squares), location of NAc neurons that responded only to stimulation of the fimbria (black circles), and neurons that received input from both the hippocampus and BLA (black and gray circles), recorded from control rats and rats whose data are presented in Figures $3 A-D$ and $4 C$. Brain sections correspond to the atlas of Paxinos and Watson (1997). Numbers correspond to millimeters from bregma. $B, C$, Photograph of a representative placement of a stimulating electrode in the fimbria $(B)$ and the BLA $(C)$. Arrows highlight the location of stimulating electrode placements. $c c$, Corpus callosum; $C P u$, caudate putamen; opt, optic tract.

cological antagonists, separate groups of rats were implanted with intravenous jugular catheters, consisting of PE 10 tubing attached to a 30 gauge needle and a $1 \mathrm{cc}$ syringe. During these experiments, no electrochemical recordings were obtained. Unless otherwise specified, all drugs were administered 10-15 min before tetanic stimulation of the fimbria. The selective $\mathrm{D}_{1}$ receptor antagonist SCH23390 (0.5, 0.05 , or 0.005 $\mathrm{mg} / \mathrm{kg}$; Research Biochemicals, Natick, MA) and the selective NMDA receptor antagonist CPP (1.0 or $0.1 \mathrm{mg} / \mathrm{kg}$; Research Biochemicals) were dissolved in physiological saline. The selective $D_{2}$ receptor antagonist sulpiride $(5.0 \mathrm{mg} / \mathrm{kg}$; Research Biochemicals) was dissolved in a drop of $\mathrm{NaOH}$ and PBS. The adenosine $\mathrm{A}_{1}$ receptor antagonist 8-cyclopentyl1,2-dimethylxanthine (DPCPX) $(2.5 \mathrm{mg} / \mathrm{kg}$; Research Biochemicals) was dissolved in DMSO. The concentrations of these solutions were set so that injection volumes would range between 0.15 and $0.30 \mathrm{ml}$. No more than two drug injections were given per animal, and in the interval between injections was at least $3.5 \mathrm{hr}$.

Histological assessment. After completion of each experiment, an iron deposit was made in the fimbria and BLA stimulation sites by passing DC current $(100 \mu \mathrm{A}$ for $10 \mathrm{sec})$ through the stimulating electrode. A dye deposit was made in the NAc recording site by ejecting Fast Green with a $20 \mu \mathrm{A}$ anodal current for $10 \mathrm{~min}$. The brain was removed and placed in $10 \%$ buffered formalin containing $0.1 \%$ potassium ferricyanide. After fixation, $50 \mu \mathrm{m}$ sections were cut on a freezing microtome and stained for Nissl substance with cresyl violet. A Prussian Blue spot resulting from a redox reaction of ferricyanide marked the stimulation site. The placements of electrochemical recording electrode, glass microelectrode, and stimulating electrodes were determined under a light microscope and are represented in Figure 1.
Data analysis. For the electrochemical recordings, pre-tetanus baseline currents were normalized to zero current values, and stimulated changes in the baseline signal were presented as absolute changes (increases as positive and decreases as negative values) in DA oxidation current. These data were analyzed using a one-way, repeated measures ANOVA with time as a within-subjects factor. Multiple comparisons were made versus the sample taken 2 min before tetanus and for data points at time 0 (tetanus) and at time points when either the fimbria or BLA were stimulated at $2 \mathrm{~Hz}$. Analysis of the extracellular recording data required that pre-tetanus baseline spike probabilities be normalized to the spike probability of the sample 2 min before tetanus, so that the relative change in spike probability at this time point would be 0 . These data were then converted to percent change in spike probability, using the formula: (sample spike probability - baseline spike probability) $\div$ baseline spike probability. Thus, a $+100 \%$ change in spike probability after fimbria tetanus would indicate that twice as many action potentials were elicited over a 100 pulse train of $2 \mathrm{~Hz}$ stimulation, relative to the number of action potentials that were observed using the same stimulation current before tetanus. Statistical comparisons were made with the spike probability recorded $7 \mathrm{~min}$ before tetanus.

Data obtained from cells which responded only to fimbria stimulation but not the BLA were analyzed using a two-way, between- and withinsubjects ANOVA, with drug condition as the between-subjects factor and time as the within-subjects factor. Data from neurons that received converging input from both the fimbria and BLA were analyzed using a three-way, between- and within-subjects ANOVA, with drug condition as the between-subjects factor, and time and input (fimbria or BLA) as two within-subjects factors. Multiple comparisons for both the electrochem- 
ical and electrophysiological analyses were made using two-tailed Dunnett's test for repeated measures.

\section{RESULTS}

\section{Dopaminergic and glutamatergic mechanisms mediating the potentiation of hippocampal-evoked spiking activity of NAc neurons}

Data from a total of 93 NAc neurons that responded only to stimulation of the fimbria, but not the BLA, were used in the present analysis (63\% of all neurons tested). In these cells, fimbria stimulation evoked a short-latency, monosynaptic spike (latency range, 6-11 $\mathrm{msec}$ ), and in some cells, a longer latency polysynaptic spike (latency range, $19-31 \mathrm{msec} ; n=33$; see Mulder et al., 1998). The mean baseline spike probability for all cells was $0.464 \pm 0.02$. The baseline spike probabilities did not differ between treatment groups $\left(F_{(8,61)}=0.99\right.$; NS).

The initial experiment assessed the effect of tetanic stimulation of the fimbria on both changes in mesoaccumbens DA release and fimbria-evoked neuronal spiking activity. Extracellular single unit recordings were obtained from nine individual NAc neurons that responded to stimulation of the fimbria, but not the BLA. These recordings were taken from six rats that had electrochemical recording electrodes implanted into the ipsilateral NAc. Tetanic stimulation of the fimbria resulted in a transient increase in DA efflux that was time-locked to the presentation of the tetanus. This was followed promptly by a brief period of inhibition, and then a second, more prolonged increase in DA efflux that was significantly elevated 25 min after tetanic fimbria stimulation, as reported previously (Blaha et al., 1997) $\left(F_{(7,42)}=3.6, p<0.005\right.$ and Dunnett's, $p<0.05$ ) (Fig. $2 A$ ). In seven of nine $(78 \%)$ NAc neurons recorded simultaneously with electrochemical measures of DA oxidation currents, tetanic stimulation of the fimbria also produced a robust short-term potentiation (lasting $25 \mathrm{~min}$ ) in fimbria-evoked spiking activity $\left(F_{(6,48)}=2.2, p<0.05\right.$ and Dunnett's, $p<0.01$ ) (Fig. 2B,C). Thus, high-frequency stimulation of glutamatergic hippocampal inputs to the NAc increased mesoaccumbens DA release, which was accompanied by an increase in the excitability of NAc neurons in response to fimbria stimulation.

To ascertain the receptor mechanisms mediating the potentiation of hippocampal-evoked spiking activity, separate groups of rats (86 cells recorded from 65 animals) received intravenous administration of selective DA or NMDA receptor antagonists. The overall analysis of these data revealed a significant time $\times$ drug treatment interaction $\left(F_{(6,366)}=1.9 ; p<0.001\right)$.

Injection of the $\mathrm{D}_{1}$ antagonist SCH $23390(0.5 \mathrm{mg} / \mathrm{kg})$ abolished the potentiation of fimbria-evoked spiking activity in all cells tested (nine of nine; 100\%). Furthermore, pretreatment with $\mathrm{SCH} 23390$ resulted in a significant $(p<0.01)$ long-lasting depression in fimbria-evoked spiking activity (eight of nine neurons; $89 \%$ ) that lasted throughout the 25 min recording session (Fig. $3 A, B)$. The effects of SCH23390 were dose-dependent ( $n=6$ for each dose) (Table 1). This depression was not caused by a nonselective action of SCH23390 by itself, because injection of SCH23390 without applying fimbria tetanus produced no significant change in firing activity evoked by $2 \mathrm{~Hz}$ fimbria stimulation $\left(n=5 ; F_{(7,28)}=0.28, \mathrm{NS}\right)$ (Fig. $\left.3 E\right)$. Injections of the $\mathrm{D}_{2}$ receptor antagonist sulpiride alone $(5 \mathrm{mg} / \mathrm{kg})$ did not block the potentiation of fimbria-evoked spiking activity by fimbria tetanus, observed in 7 of 11 neurons (63\%) (Fig. 3A). However, SCH23390 $(0.5 \mathrm{mg} / \mathrm{kg})$ and sulpiride $(5 \mathrm{mg} / \mathrm{kg})$ in combination resulted in only a transient $(2 \mathrm{~min})$ post-tetanic depression of fimbria-evoked activity $(n=8)$ (Fig. $3 A$ ). It is also noteworthy that repetitive
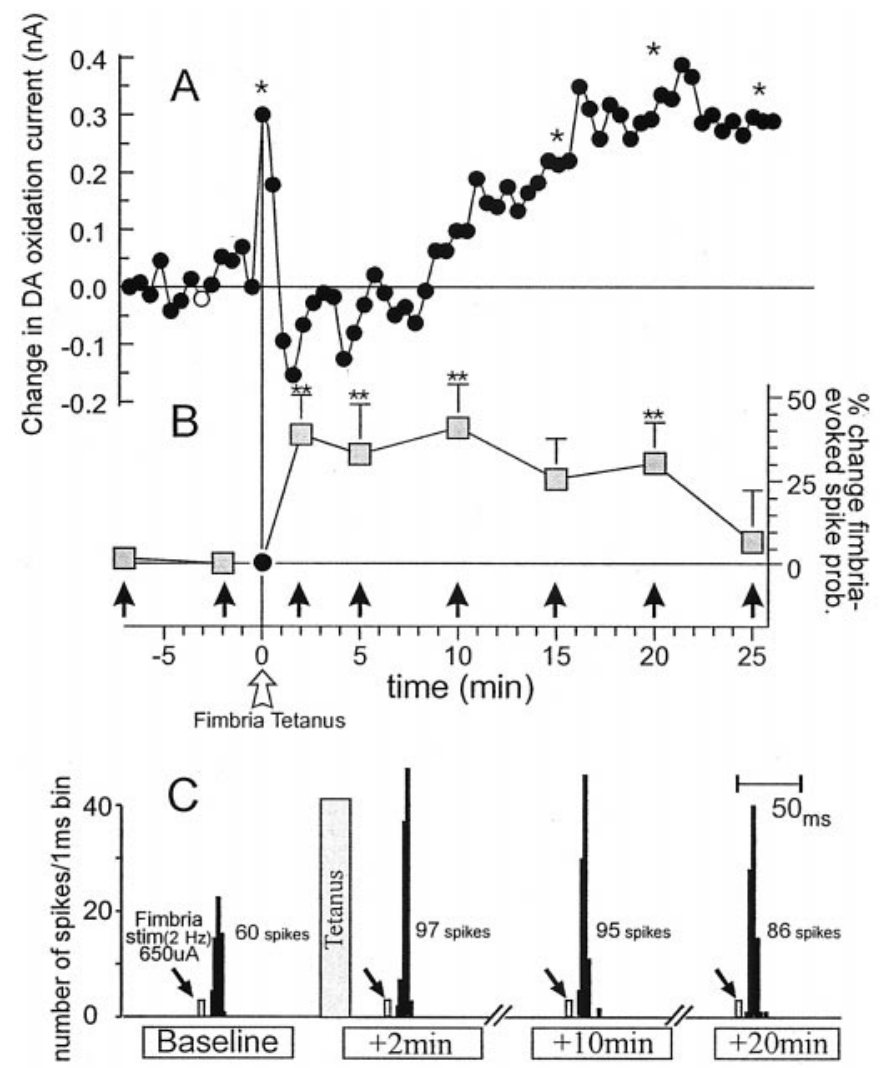

Figure 2. Tetanic stimulation of hippocampal afferents in the fimbria increases mesoaccumbens DA efflux and enhances hippocampal-evoked spiking activity in NAc neurons. $A$, Mean changes in DA oxidation currents in the NAc recorded by chronoamperometry. Tetanic stimulation of the fimbria $(20 \mathrm{~Hz}, 10 \mathrm{sec}$; open arrow) produced a significant increase in DA efflux. Asterisks denote significant difference from baseline (white circle) at $p<0.05$. B, Mean percent change (+ SEM) in fimbria-evoked spiking activity recorded from NAc neurons in the same animals from which the chronoamperometric recordings were obtained. Gray squares represent percent change in fimbria-evoked spiking probability normalized to the spike probability obtained $2 \mathrm{~min}$ before tetanus. Vertical filled arrows indicate time points at which trains of $2 \mathrm{~Hz}$ fimbria stimulation were administered. Double asterisks denote significance from baseline spike probability (sample $7 \mathrm{~min}$ before tetanus) at $p<0.01$. $C$, Peristimulus time histograms showing the typical response from a NAc neuron 2 min before and 2, 10, and $20 \mathrm{~min}$ after fimbria tetanus. This neuron displayed a baseline spiking probability of 0.6 at a stimulation current of $650 \mu \mathrm{A}$. After tetanic stimulation of the fimbria (gray bar), the spiking probability of the neuron (at the same stimulation current) was increased to $\sim 1.0$. Arrows represent time points when trains of $2 \mathrm{~Hz}$ fimbria stimulation were administered.

trains of $2 \mathrm{~Hz}$ stimulation of the fimbria over a $20 \mathrm{~min}$ period without tetanic stimulation produced no change in fimbriaevoked spiking activity (Fig. $3 E$ ), indicating that repeated trains of $2 \mathrm{~Hz}$ stimulation do not produce changes in synaptic efficacy in the NAc.

The enhancement of the response of NAc neurons to fimbria stimulation was critically dependent on the initial increase in DA efflux that occurred coincidentally with tetanic activation of hippocampal inputs. Administration of SCH23390 (0.5 mg/ kg) $3 \mathrm{~min}$ after fimbria tetanus, before the secondary prolonged increase in NAc DA efflux, failed to block the potentiation of fimbria-evoked spiking activity in all neurons tested $\left(n=7 / 7,100 \% ; F_{(7,35)}=3.0\right.$, $p<0.05$ ) (Fig. 3D). In fact, injections of SCH23390 after tetanus prolonged the time course of the potentiation, with all cells 


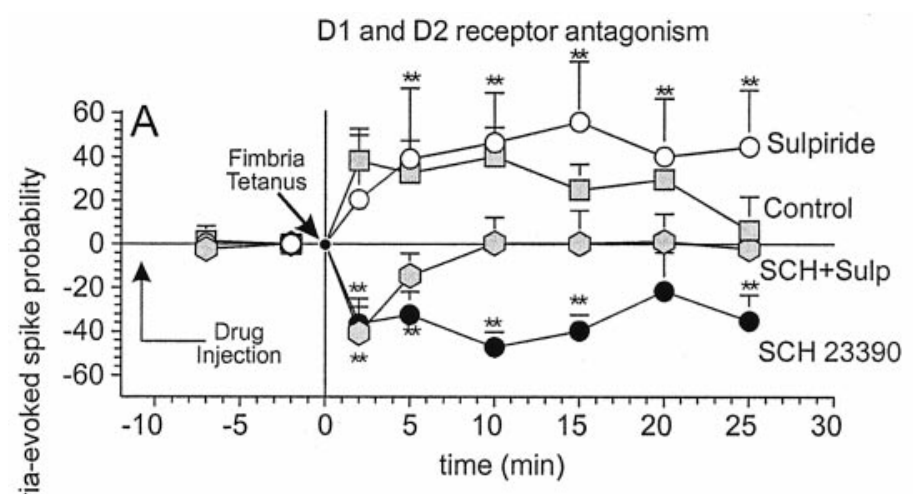

D1 antagonism, individual data
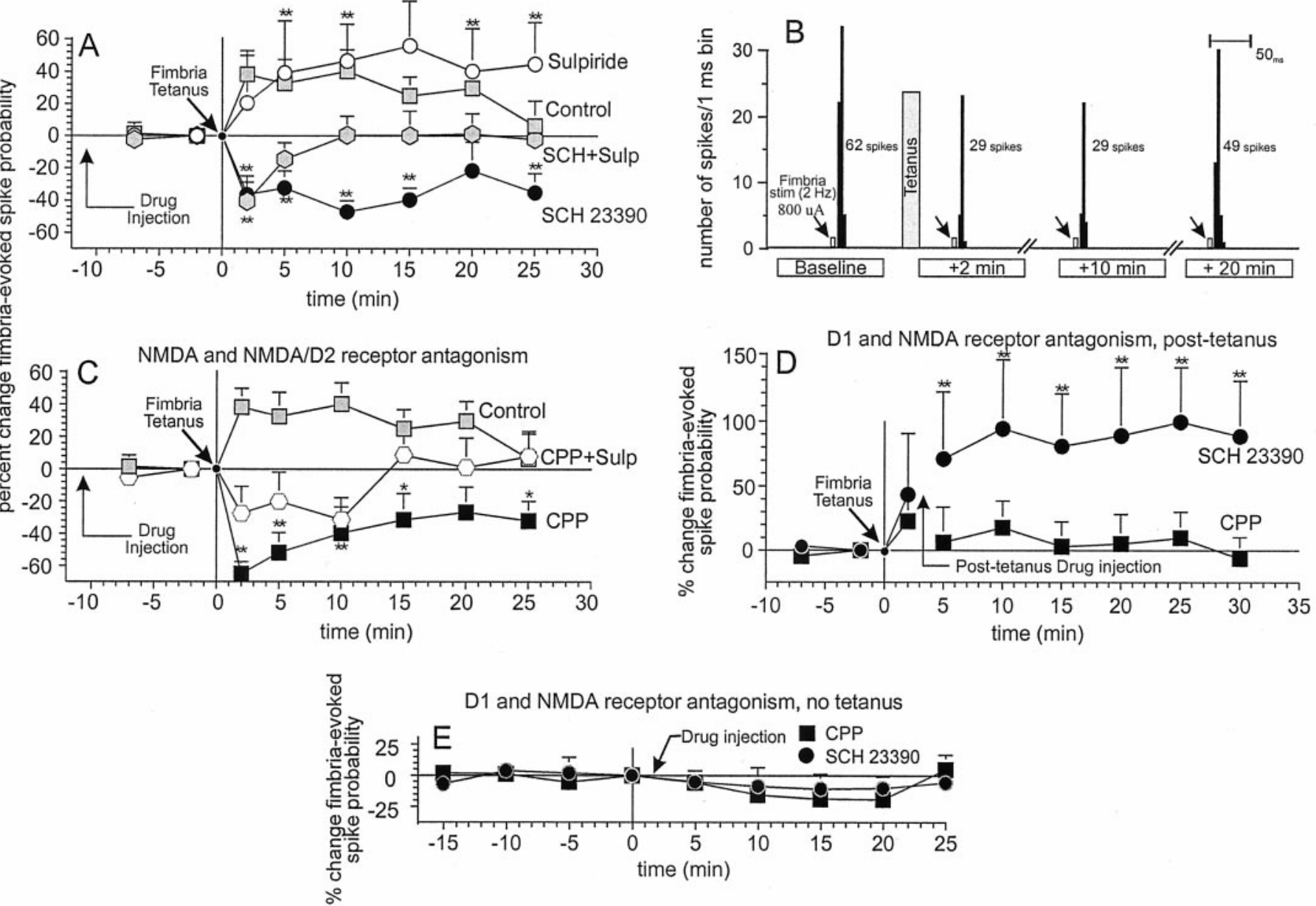

Figure 3. Potentiation of hippocampal-evoked spiking activity in NAc neurons is dependent on both $\mathrm{D}_{1}$ and NMDA receptors. For all figures, symbols represent mean percent change $(+\mathrm{SEM})$ in fimbria-evoked spiking activity of NAc neurons. $A$, Change in fimbria-evoked spiking activity under control conditions (gray squares) and after treatment with the $\mathrm{D}_{1}$ receptor antagonist $\mathrm{SCH} 23390\left(0.5 \mathrm{mg} / \mathrm{kg}\right.$; black circles), the $\mathrm{D}_{2}$ receptor antagonist sulpiride $(5.0 \mathrm{mg} / \mathrm{kg}$; white circles), and a combination of SCH23390 and sulpiride (gray hexagons). Arrow in the bottom left corner indicates time point of drug injection. $B$, Peristimulus time histograms showing a typical response from a single NAc neuron pretreated with SCH23390 10 min before tetanus, at baseline ( 2 min before), and 2, 10, and 20 min after fimbria tetanus. Baseline spiking probability was 0.62 ( $800 \mu \mathrm{A}$ ), and after fimbria tetanus ( $g r a y$ bar), the spiking probability decreased by $>50 \%$. Arrows represent time points at which trains of $2 \mathrm{~Hz}$ fimbria stimulation were administered. $C$, Change in fimbria-evoked spiking from control neurons ( gray squares), after pretreatment with the NMDA receptor antagonist CPP (1.0 mg $/ \mathrm{kg}$; black squares), and after pretreatment with a combination of CPP and sulpiride (white hexagons). $D$, Change in fimbria-evoked spiking activity after post-tetanus injection of SCH23390 (black circles) or CPP (black squares). Arrow indicates time point when the drugs were administered (3 min after tetanus). E, Change in fimbria-evoked spiking activity recorded from NAc neurons after $20 \mathrm{~min}$ of $2 \mathrm{~Hz}$ stimulation in the absence of drug and another $25 \mathrm{~min}$ of $2 \mathrm{~Hz}$ stimulation after injection of either SCH 23390 or CPP. For all figures, double asterisks denote significance from baseline spiking probabilities at $p<0.01$ (Dunnett's test).

displaying an enhancement of evoked spiking activity $30 \mathrm{~min}$ after tetanus. Collectively, these data indicate that the short-term potentiation of hippocampal-evoked spiking activity in NAc neurons after tetanic stimulation of the fimbria is mediated by the transient increase in DA efflux that is time-locked to the arrival of higher frequency inputs. Of particular interest is the finding that during $D_{1}$ receptor blockade, activation of $D_{2}$ receptors resulted in a long-lasting depression ( $>30 \mathrm{~min}$ ) of evoked spiking activity, as may be inferred from the reversal of this effect by coadministration of sulpiride.

Previous studies have shown that synaptic plasticity in the hippocampal-NAc pathway is dependent on NMDA receptor activation (Pennartz et al., 1993; Feasy-Trugger and ten Bruggencate, 1994). In accordance with these findings, the NMDA receptor antagonist CPP [1.0 $(n=7)$ or $0.1(n=6) \mathrm{mg} / \mathrm{kg}$, i.v. $]$ produced a dose-dependent effect similar to that of SCH23390, because it blocked the tetanus-induced potentiation of fimbriaevoked spiking activity and caused a significant $(p<0.01)$, long-lasting depression of fimbria-evoked spiking activity in $100 \%$ of the neurons tested (Fig. 3C, Table 1). CPP alone without fimbria tetanus had no significant effect on fimbria-evoked spiking activity $(n=5)$ (Fig. $3 E)$. As observed after fimbria tetanus in the presence of $D_{1}$ receptor blockade, $D_{2}$ receptors again played a role in the inhibition of evoked spiking activity after NMDA receptor blockade. Coadministration of CPP and sulpiride (5 $\mathrm{mg} / \mathrm{kg})$ resulted in a shorter lasting ((10 min), nonsignificant reduction in fimbria-evoked spiking activity (Fig. $3 C$ ).

Unlike the effects observed with SCH23390, administration of CPP 3 min after tetanus abolished or attenuated the potentiation of fimbria-evoked spiking activity in six of seven neurons $(86 \%)$ 


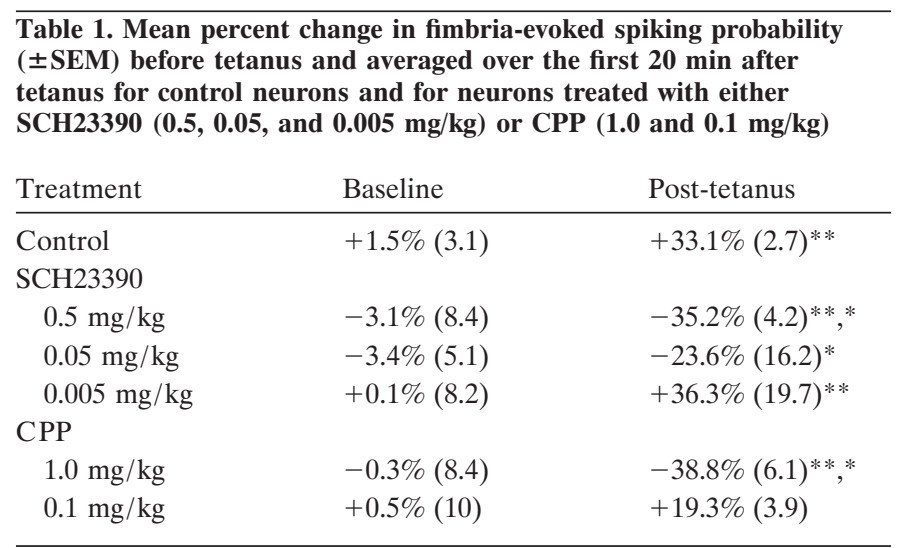

*Denotes $p<0.05$ vs control neurons.

${ }^{* *}$ Denotes $p<0.01$ vs baseline.

tested $\left(F_{(7,42)}=0.5, \mathrm{NS}\right)($ Fig. $2 D)$. This confirms that activation of NMDA receptors is necessary for both the induction and maintenance of the DA-mediated potentiation of fimbria-evoked spiking activity in NAc neurons. A separate series of experiments demonstrated that a systemic injection of CPP did not block mesoaccumbens DA efflux evoked by tetanic stimulation of the fimbria ( $n=6$; mean peak increases in DA oxidation current, control $=0.83 \mathrm{nA}, \mathrm{CPP}=0.90 \mathrm{nA}$ ). It should be noted however that intra-NAc administration of APV has been shown to block increases in mesoaccumbens DA efflux evoked by tetanic stimulation of hippocampal inputs to the NAc in both anesthetized (Blaha et al., 1997) and freely moving rats (Taepavarapruk et al., 2000). The lack of effect in the present study suggests that at the present dose, route of administration, or specific pharmacological actions of this NMDA antagonist (i.e., CPP) was not sufficient to block hippocampal-mediated DA release that is regulated by NMDA receptors in the NAc. Thus, the potentiation of hippocampal-evoked spiking activity of NAc requires a cooperative action of both $\mathrm{D}_{1}$ and NMDA receptors, and after blockade of either of these receptors, there remains a $\mathrm{D}_{2}$-receptor mediated reduction in cell excitability.

\section{The role of dopamine in homosynaptic facilitation of hippocampal-evoked spiking activity and heterosynaptic depression of BLA-evoked activity of NAc neurons}

A sub-population of NAc neurons receives converging input from both the hippocampus and the BLA (Callaway et al., 1991; O'Donnell and Grace, 1995; Mulder et al., 1998). Tetanic stimulation of the fimbria can evoke long-term potentiation of fimbriaevoked field potentials in the NAc while simultaneously causing long-term depression of the BLA-NAc pathway (Mulder et al., 1998). The latter study did not specify whether the homosynaptic potentiation of the hippocampal inputs and heterosynaptic depression of the BLA inputs to the NAc occurs in neurons that receive converging input from both regions. Moreover, the underlying cellular mechanisms that mediated these opposing effects on synaptic plasticity of limbic inputs to the NAc are poorly understood. In light of the present data, showing that tetanic stimulation of fimbria results in DA-dependent changes in evoked firing activity of NAc neurons, it is possible that the opposing effects on synaptic plasticity of different converging inputs to the NAc were mediated in part by mesoaccumbens DA transmission. Therefore, extracellular single-unit recordings were made from
55 NAc neurons (37\% of all cells) that received converging input from both the hippocampus and BLA.

Stimulation of the fimbria produced a robust excitatory response with spike latencies that were similar to those observed in neurons that only responded to fimbria stimulation. These cells also exhibited monosynaptic responses to BLA stimulation (latency range, $11-29 \mathrm{msec}$ ). The mean baseline spike probability for all cells was $0.502 \pm 0.02$ for fimbria-evoked responses and $0.533 \pm 0.03$ for BLA-evoked responses $\left(F_{(1,49)}=0.76 ; \mathrm{NS}\right)$. The baseline spike probabilities for both fimbria- and BLA-evoked spiking activity did not differ between treatment groups $\left(F_{(5,49)}=\right.$ 0.16 ; NS). We were unable to record from three control cells continuously for the entire $25 \mathrm{~min}$ recording period. Thus, only the data from the first 15 min after tetanus were used in this analysis.

In six rats, tetanic stimulation of the fimbria produced a transient increase in DA efflux, as measured by chronoamperometry, that was time-locked to the presentation of the tetanus, followed by a longer lasting decrease in extracellular DA levels $\left(F_{(5,35)}=\right.$ $4.69, p<0.005$ and Dunnett's, $p<0.05)$. Interestingly, when both the fimbria and BLA were stimulated at $2 \mathrm{~Hz}$ after fimbria tetanus, the prolonged increase in DA release that was observed previously (Blaha et al., 1997) (Fig. 2A) was absent after this stimulation protocol (Fig. $4 A$ ). This effect may be attributable to activation of metabotropic glutamate receptors by low frequency stimulation of both hippocampal and BLA inputs to the NAc (Blaha et al., 1997; Floresco et al., 1998).

In these same animals, fimbria-evoked spiking activity of NAc neurons was potentiated, in a manner similar to that described above, which was apparent 1 min after tetanus (eight of nine neurons, $89 \%$ ) (Fig. 4B, black bars). However, tetanic stimulation of the fimbria resulted in a depression of BLA-evoked spiking activity, in these same neurons (seven of nine neurons; 78\%) (Fig. $4 B$, gray bars) (time $\times$ input interaction, $F_{(3,24)}=6.9, p<0.01$ and Dunnett's, $p<0.01)$. BLA-evoked spiking activity was depressed maximally ( $\sim 50 \%$ decrease) during the sample taken immediately after fimbria tetanus, when DA oxidation currents reached peak values and slowly returned to baseline levels over the next $10-15 \mathrm{~min}$.

Separate pharmacological experiments $(n=34$ rats) revealed that both the potentiation of fimbria-evoked spiking activity and suppression of BLA-evoked spiking activity after fimbria tetanus were abolished by pretreatment with SCH23390 $(0.5 \mathrm{mg} / \mathrm{kg}$, i.v.; $n=9$ ) (Fig. $4 C$ ), suggesting that $\mathrm{D}_{1}$ receptors mediate both of these effects. However, considering the dose of SCH23390 used in this experiment, we cannot rule out the possibility that a 5-HT2 receptor mechanism may also play a role in the suppression of BLA-evoked activity (Bischoff et al., 1986). Injections of sulpiride (5 mg/kg; $n=11$ ) had no effect (Fig. 4C). CPP blockade of NMDA receptors $(1.0 \mathrm{mg} / \mathrm{kg} ; n=9)$, abolished the potentiation of fimbria-evoked spiking activity, but had no effect on the suppression of BLA-evoked spiking activity (Fig. 4C).

Presynaptic inhibition of glutamatergic inputs to the NAc by $D_{1}$ receptor activation can be co-mediated by adenosine, acting as a retrograde messenger to inhibit glutamate inputs presynaptically via the $A_{1}$ receptor (Harvey and Lacey, 1997). We observed that the adenosine $\mathrm{A}_{1}$ antagonist DPCPX $(2.5 \mathrm{mg} / \mathrm{kg}$, i.v.) markedly reduced the suppression of BLA-evoked spiking activity after fimbria tetanus in a separate group of neurons $(n=10)$ but had no effect on the potentiation of hippocampal-evoked spiking activity (Fig. 4C). This is consistent with the role of adenosine as an inhibitory retrograde signal. Thus, a brief increase in DA efflux 


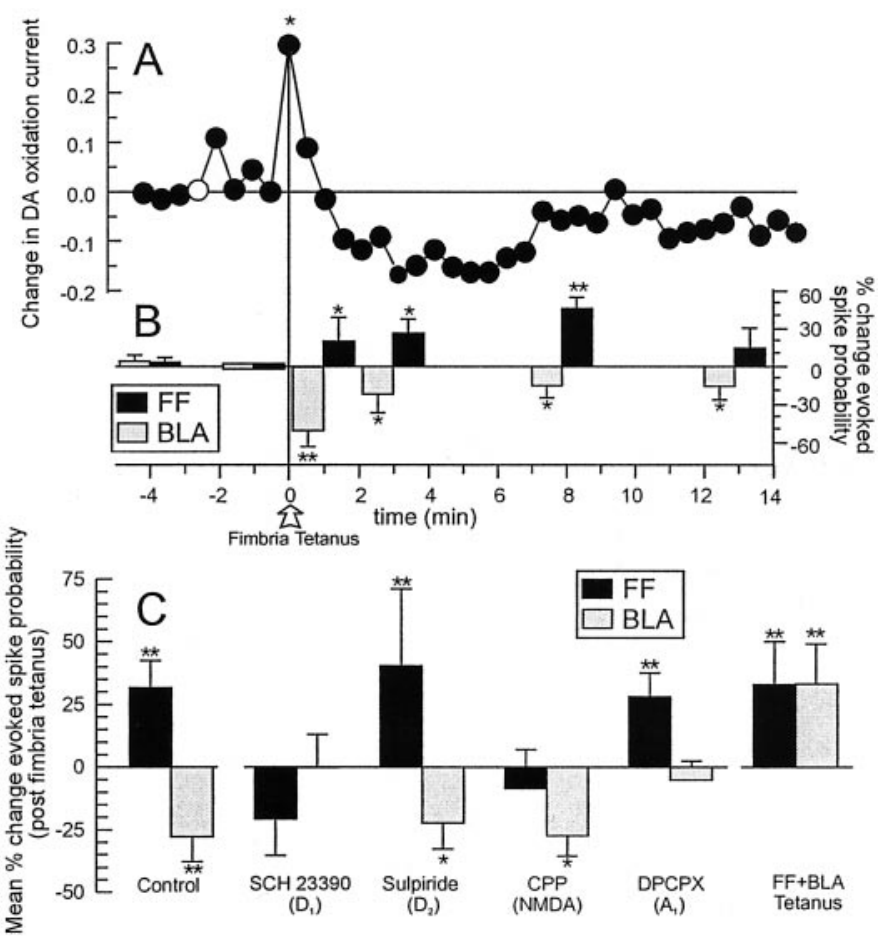

Figure 4. Tetanic stimulation of the fimbria increases mesoaccumbens DA efflux, enhances neural activity evoked by fimbria stimulation, and suppresses BLA-evoked spiking activity of NAc neurons. $A$, Mean changes in DA oxidation currents in the NAc recorded by chronoamperometry. Tetanic stimulation of the fimbria (open arrow) produced a significant increase in DA efflux. Asterisks denote significant difference from baseline (white circle) at $p<0.05 . B$, Mean percent change ( \pm SEM) in fimbria (black bars)- and BLA (gray bars)-evoked spiking activity recorded from NAc neurons that received converging input from both brain regions. Histograms represent percent change in fimbria- and BLAevoked spiking probability normalized to the spike probabilities obtained 2 min before tetanus. Location of the histograms on the abscissa indicates time points at which trains of $2 \mathrm{~Hz}$ stimulation of either the fimbria or BLA were administered. Tetanic stimulation of the fimbria increased fimbria-evoked spiking probability while suppressing BLA-evoked spiking activity in the same neurons. $C$, Mean percent change $( \pm$ SEM) in fimbria (black histograms) and BLA-evoked (gray) spiking activity recorded from NAc neurons averaged over the first $12 \mathrm{~min}$ after fimbria tetanus for control treatment, SCH23390 (0.5 mg/kg), sulpiride $(5.0 \mathrm{mg} / \mathrm{kg}), \mathrm{CPP}$ $(1.0 \mathrm{mg} / \mathrm{kg})$, the adenosine $\mathrm{A}_{1}$ antagonist DPCPX $(2.5 \mathrm{mg} / \mathrm{kg})$, and tetanic stimulation of both the fimbria and the BLA. Baseline spike probabilities for each condition have been omitted for clarity. Asterisks and double asterisks denote significance from baseline spike probability (sample $7 \mathrm{~min}$ before tetanus) at $p<0.05$ and 0.01 , respectively.

evoked by high-frequency activity in hippocampal afferents to the NAc is sufficient to enhance fimbria-evoked spiking activity, while simultaneously causing a suppression of BLA-evoked spiking activity in the same neurons. The homosynaptic potentiation of hippocampal evoked activity requires both $\mathrm{D}_{1}$ and NMDA receptor activity, whereas the heterosynaptic suppression of BLAevoked firing is dependent on both $D_{1}$ and adenosine $A_{1}$ receptors.

The differential modulation by DA over hippocampal and BLA-evoked activity may have been attributable to the fact that there was a selective increase in the activity in the hippocampalNAc pathway at the time when DA was released, while at the same time, inputs from the BLA were quiescent. It follows therefore that the inhibitory effects of DA on BLA-evoked spiking activity should be reversed if BLA inputs were active at the time of DA release. Consistent with this hypothesis, coincidental tetanic stimulation of both the fimbria and the BLA [100 pulses for each input, alternating bursts, 10 bursts at 10 pulses per burst $(20 \mathrm{~Hz}), 500 \mathrm{msec}$ interburst interval] resulted in potentiation of both hippocampal and BLA-evoked spiking activity in the same neurons $(n=7)$ (Fig. $4 C$ ). We have shown previously that tetanic stimulation of the BLA evoked an increase in mesoaccumbens DA efflux (Floresco et al., 1998), and a separate study confirmed that the potentiation of BLA-evoked spiking activity after BLA tetanus was mediated by the $\mathrm{D}_{1}$ receptor (Blaha et al., 1998).

\section{DISCUSSION}

The present data suggest that DA transmission in the NAc plays a critical role in an input selection mechanism that permits certain inputs to have preferential, but temporary, influence over neural activity in the NAc. Higher-frequency activity in the glutamatergic hippocampal-NAc pathway can directly facilitate the release of mesoaccumbens DA. This transient increase in NAc DA activity, which is time-locked to the tetanic depolarization of NAc neurons, is sufficient to facilitate subsequent hippocampal-evoked neural activity of NAc neurons, whereas the subsequent increase in DA does not appear to play a role in this potentiation. Furthermore, the cooperative interaction between $\mathrm{D}_{1}$ and NMDA receptors plays a key role in this potentiation. Blockade of either $\mathrm{D}_{1}$ or NMDA receptors reveals a $\mathrm{D}_{2}$-mediated suppression of fimbria-evoked spiking activity. In addition, DA release facilitated by high-frequency hippocampal inputs also exerts an activity-dependent inhibition of BLA inputs converging on the same NAc neuron. This effect may occur via a presynaptic mechanism that involves a cooperative interaction between $D_{1}$ and adenosine $A_{1}$ receptors. Therefore, the modulation of mesoaccumbens DA release by hippocampal afferents provides an intrinsic activity-dependent coincidence detection mechanism. The release of DA that occurs when this input pathway is active serves two functions: the hippocampal input is amplified, whereas subsequent activity in BLA projections to the same neuron is inhibited.

\section{Cellular mechanisms for the DA-mediated potentiation of hippocampal-NAc pathway}

There are a number of potential cellular mechanisms by which $\mathrm{D}_{1}$ receptor activation could facilitate hippocampal evoked-spiking activity of NAc neurons. These include (1) inhibition of $\mathrm{Na}^{+} /$ $\mathrm{K}^{+}$ATPase (Betrorello et al., 1990), (2) enhancement of L-type $\mathrm{Ca}^{2+}$ channels (Hernández-López et al., 1997; Cepeda and Levine, 1998), or (3) direct augmentation of NMDA receptor activity via phosphorylation of NMDA channels by protein kinase A and C-mediated second messenger cascades (Blank et al., 1997; Cepeda and Levine, 1998; Chergui and Lacey, 1999). Thus, activation of $D_{1}$ receptors after DA release, in combination with tetanic depolarization of NAc neurons (both of which are achieved by stimulation of hippocampal afferents), could activate a number of different cellular mechanisms that would lead to a longer lasting depolarization of these cells. Under these circumstances, medium spiny neurons are more responsive to subsequent stimulation of glutamate inputs from the hippocampus, thereby increasing probability of cell firing (Fig. 5). Blockade of NMDA receptors, either before or after tetanic stimulation of the fimbria, abolished the potentiation of hippocampal-evoked activity, suggesting that the enhancement of NMDA receptor activity is involved critically in the induction and maintenance of the potentiated neuronal excitability in NAc neurons. 
Figure 5. Diagram of hippocampal, BLA, and DA inputs, synapsing on separate dendrites of an individual medium spiny neuron in the NAc, illustrating the processes that may mediate the differential effects of DA $D_{1}$ receptor activity on NAc neuron firing. On the left spine, glutamatergic inputs from the hippocampus can activate both the postsynaptic NAc dendrite and facilitate the release of DA. DA activates postsynaptic $\mathrm{D}_{1}$ receptors and can depolarize this dendrite by modulation of postsynaptic NMDA receptors. The net effect would be an enhancement of hippocampal-evoked activity. Stimulation of $\mathrm{D}_{1}$ receptors can also lead to the formation of adenosine. On the right spine, adenosine, released from the postsynaptic NAc neuron, may act as a retrograde signal (Harvey and Lacey, 1997) to inhibit glutamate inputs from the BLA, which are inactive at the time of DA release, via $A_{1}$ receptors, putatively (?) located on presynaptic glutamate terminals originating from the BLA. The net effect would be a suppression of BLA-evoked activity. The size of the arrows represents the relative strength of the response evoked by each input after DA modulation of neural activity.

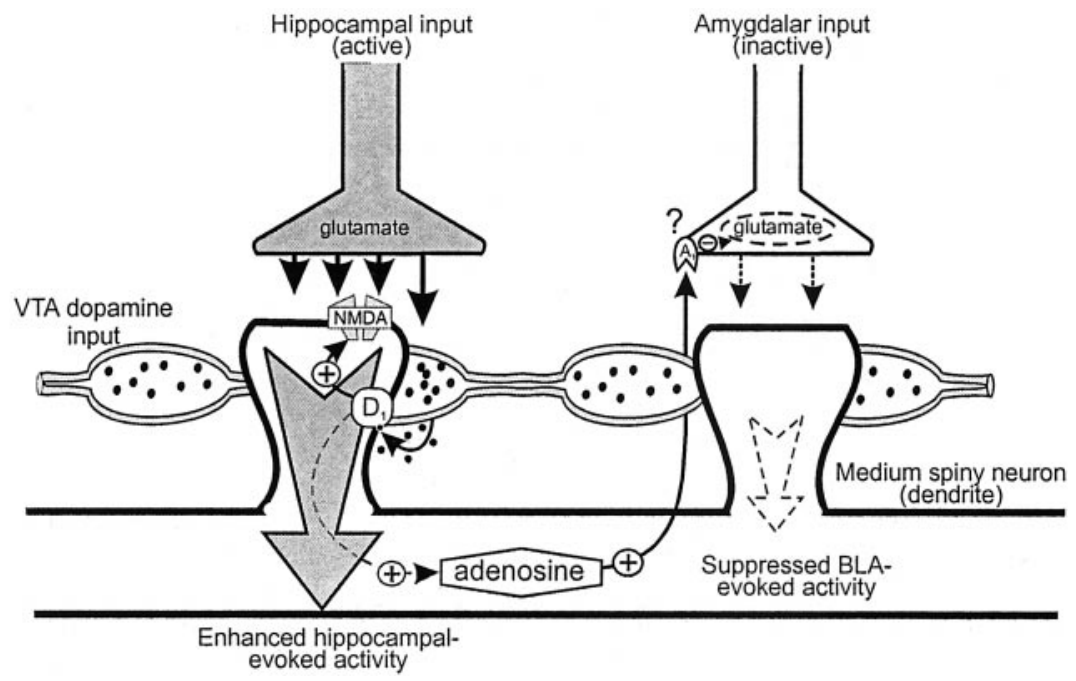

Our finding of a $\mathrm{D}_{2}$-mediated suppression of evoked firing activity after blockade of either $\mathrm{D}_{1}$ or NMDA receptors is particularly intriguing. It suggests that under some conditions, $\mathrm{D}_{1}$ and $D_{2}$ receptors may act in an antagonistic manner, with $D_{1}$ receptors promoting an increase in neural excitability and $D_{2}$ receptor activity producing an inhibition of firing. Other studies have shown a cooperative interaction between $\mathrm{D}_{1}$ and $\mathrm{D}_{2}$ receptors in the NAc (White and Wang, 1986; Hu and White, 1994). However, in these studies, DA agonists were applied iontophoretically to the NAc neurons, and coactivation of $\mathrm{D}_{1}$ and $\mathrm{D}_{2}$ receptors exerted synergistic suppressive actions on glutamateinduced firing activity. It is apparent, therefore, that in addition to inhibiting the activity of NAc neurons via a cooperative interaction with $\mathrm{D}_{2}$ receptors, $\mathrm{D}_{1}$ receptors can also facilitate neural activity by a cooperative interaction with NMDA receptors, and this can work in an opposite manner to the effects of $\mathrm{D}_{2}$ receptor stimulation. Consistent with the present findings, other studies have shown that the $\mathrm{D}_{1}$ antagonist $\mathrm{SCH} 23390$ blocks long-term potentiation of neurons in the dorsal striatum after highfrequency stimulation of corticostriatal fibers, whereas administration of the $\mathrm{D}_{2}$ antagonist sulpiride enhanced the potentiation (Calabresi et al., 2000). The competition between $\mathrm{D}_{1}$ and $\mathrm{D}_{2}$ receptors may be mediated through intracellular second messenger such as adenylyl cyclase systems or by modulation of different ionic conductances by $\mathrm{D}_{1}$ and $\mathrm{D}_{2}$ receptors (Surmeier and Kitai, 1993; Nestler, 1994; Cepeda and Levine, 1998).

\section{Activity-dependent modulation by DA over BLA- evoked activity of NAc neurons}

The present finding that DA release facilitated by high-frequency hippocampal inputs also exerts an activity-dependent suppression of BLA inputs converging on the same NAc neuron is of particular relevance to the issue of input selection. The fact that mesoaccumbens DA release enhances hippocampal-evoked activity of NAc neurons while simultaneously suppressing firing evoked by BLA stimulation suggests that the inhibitory actions of $\mathrm{D}_{1}$ receptors may occur via a presynaptic mechanism (Yim and Mogenson, 1986; Mogenson et al., 1993). However, given the use of systemic administration of antagonists in the present study, we cannot rule out the possibility that postsynaptic actions of DA may also play a role in this suppression of BLA-evoked spiking activity. Nevertheless, the hypothesis that DA inhibits BLAevoked firing presynaptically is supported by a number of in vivo and in vitro studies demonstrating that $\mathrm{DA}$ or $\mathrm{D}_{1}$ receptor agonists can inhibit glutamatergic inputs to the NAc originating from a number of limbic and cortical regions (Yang and Mogenson, 1984, 1986; Yim and Mogenson, 1986; Pennartz et al., 1991; Nicola et al., 1996; Harvey and Lacey, 1997; Nicola and Malenka, 1997).

Although the above-mentioned studies have suggested that DA inhibits synaptic activity in the NAc via a $D_{1}$-receptor mediated presynaptic mode of action, anatomical evidence demonstrating the existence of presynaptic $\mathrm{D}_{1}$ receptors on glutamate terminals in the NAc is lacking. Harvey and Lacey (1997) have reported that the presynaptic inhibition of glutamate inputs to NAc neurons produced by a $\mathrm{D}_{1}$ agonist was abolished by coadministration of the adenosine $\mathrm{A}_{1}$ receptor antagonist DPCPX. These authors concluded that postsynaptic activation of $\mathrm{D}_{1}$ receptors on medium spiny neurons leads to the formation of adenosine, which acts as a retrograde messenger to inhibit glutamate release presynaptically. A similar finding was observed in the present study, in which the inhibition of BLA-evoked spiking activity involved a cooperative interaction between $\mathrm{D}_{1}$ and adenosine $\mathrm{A}_{1}$ receptors (Fig. 5). Administration of either SCH23390 or DPCPX blocked the suppression of BLA-evoked spiking activity.

The finding that DA and adenosine-mediated suppression of BLA-evoked spiking activity was frequency- and activitydependent has important implications. When the release of DA (induced by fimbria tetanus) occurred while BLA inputs were inactive, subsequent BLA-evoked spiking activity of NAc neurons was reduced. However, when both hippocampal and BLA afferents were tetanized simultaneously, firing evoked by both afferents was potentiated. DeFrance et al. (1985) observed that ionotophoretic application of DA suppressed fimbria-evoked field potentials in the NAc when the fimbria was stimulated at a lower frequency $(1 \mathrm{~Hz})$, but had no such effect at a higher stimulation frequency $(6 \mathrm{~Hz})$. Similarly, stimulation of the DA cell bodies in the VTA inhibited hippocampal-evoked synaptic responses in the prefrontal cortex, but facilitated long-term potentiation in this pathway when the VTA was stimulated coincidentally with tetanic stimulation of the hippocampus (Gurden et al., 1999). Likewise, Wickens et al. (1996) reported that pulsatile application of DA in a corticostriatal slice, coincidental with tetanic stimulation of glutamatergic inputs, resulted in long-term potentiation of cortically evoked activity, whereas prolonged bath application of DA combined with tetanus resulted in long-term depression. It is 
apparent, therefore, that key determinants of whether DA will suppress or facilitate subsequent activity of NAc neurons evoked by a specific limbic afferent are firing frequency of the particular input and coincidental activation of $\mathrm{D}_{1}$ receptors.

Although the mechanism underlying frequency and activitydependent modulation by DA and adenosine of glutamate inputs to the NAc is unclear, these effects may be attributable to the differential effects of DA (and possibly adenosine) on ionic conductances, as a function of the membrane potential at which the neuron is operating at a given moment (Surmeier and Kitai, 1993; Hernández-López et al., 1997). With respect to the present study, it is possible that the concomitant release of DA when BLA inputs were inactive may have modulated voltage-gated ion channels located on presynaptic glutamate terminals, thereby inhibiting glutamate release. However, when the terminals were active, the voltage-gated ion channels on these terminals would undergo configurational changes that may prevent the dopaminergic and adenosinergic modulation of these ionic conductances, offsetting the inhibitory effects of these transmitters on glutamate release. As already discussed, facilitation of DA release by high-frequency activity in either hippocampal or BLA afferents to the NAc (Blaha et al., 1997; Floresco et al., 1998) would provide an inherent mechanism to ensure that an increase in mesoaccumbens DA release occurs coincidentally with the glutamatergic activation of the postsynaptic NAc neuron by a specific limbic afferent. It is interesting to note that a similar mechanism appears to mediate synaptic plasticity in the hippocampal-prefrontal cortical pathway, whereby tetanic stimulation of the ventral subiculum results in an increase in mesocortical DA efflux and $\mathrm{D}_{1}$ receptor dependent long-term potentiation of hippocampal afferents to the prefrontal cortex (Gurden et al., 2000).

\section{Functional implications}

The present finding that $\mathrm{D}_{1}$ receptor activity can exert opposite effects on hippocampal and amygdalar inputs synapsing on the same neuron in the NAc highlights the importance of the mesoaccumbens DA system in input selection. These data are consistent with contemporary theory regarding the function of DA transmission in the basal ganglia, which postulates that $D_{1}$ receptor activity serves to strengthen the most salient inputs while at the same time inhibiting weaker inputs (Oades, 1985; Schultz, 1998; Nicola et al., 2000). The present findings also highlight the importance of the timing of DA release, coincidental to the arrival of higher-frequency glutamatergic inputs to NAc neurons. DA can potentiate active glutamatergic inputs while inhibiting those inputs that are inactive when $D_{1}$ receptor stimulation occurs. It is noteworthy that the facilitatory effect of DA on the evoked activity of NAc neurons is consistent with psychopharmacological data, which show that enhanced mesoaccumbens DA transmission can exert a "gain-amplifying effect" on behaviors that are mediated by limbic-striatal circuits, thereby facilitating the influence that information processed by the hippocampus exerts over patterns of behavior mediated by the ventral striatum (Robbins and Everitt, 1996; Floresco and Phillips, 1999). A combination of selective amplification and inhibition of separate limbic inputs synapsing on the same NAc neurons is also consistent with the hypothesis that the mesoaccumbens DA system plays an important role in response selection or behavioral switching (Oades, 1985; Van de Bos et al., 1991; Pennartz et al., 1994; Salamone et al., 1997; Ikemoto and Panksepp, 1999; Redgrave et al., 1999). Redgrave et al. (1999) have proposed that DA "could assist in preparing the animal to deal with the unex- pected by promoting the switching of attentional and behavioral resources toward biologically significant stimuli." Accordingly, activity-dependent modulation by DA of limbic afferents to the ventral striatum may represent a cellular mechanism for input selection that governs the smooth coordination of behavior, by permitting information processed by one cognitive system to have preferred access to the motor systems via the NAc and thereby temporarily exert control over the type and intensity of adaptive behavioral responses.

\section{REFERENCES}

Betrorello AM, Hopfield JF, Aperia A, Greengard P (1990) Inhibition by dopamine of $(\mathrm{Na}(+)+\mathrm{K}+)$ ATPase activity in neostriatal neurons through $\mathrm{D}_{1}$ and $\mathrm{D}_{2}$ dopamine receptor synergism. Nature 347:386-388.

Bischoff S, Heinrich M, Sonntag J-M, Krauss J (1986) The $\mathrm{D}_{1}$ dopamine receptor antagonist SCH23390 also interacts potently with brain serotonin (5-HT2) receptors. Eur J Pharmacol 129:367-370.

Björklund A, Lindvall O (1984) Dopamine-containing systems in the CNS. In: Handbook of chemical neuroanatomy: classical transmitters in the rat, Vol 2 (Björklund A, Hökfelt T, eds), pp 55-122. Amsterdam: Elsevier/North Holland.

Blaha CD, Phillips AG (1996) A critical assessment of electrochemical procedures applied to the measurement of dopamine and its metabolites during drug-induced and species-typical behaviours. Behav Pharmacol 7:675-708.

Blaha CD, Yang CR, Floresco SB, Barr AM, Phillips AG (1997) Stimulation of the ventral subiculum of the hippocampus evokes glutamate receptor-mediated changes in dopamine efflux in the rat nucleus accumbens. Eur J Neurosci 5:902-911.

Blaha CD, Floresco SB, Yang CR, Phillips AG (1998) Hippocampal and amygdala-evoked changes in synaptic plasticity of nucleus accumbens neurons: correlations with limbic-evoked dopamine efflux. Soc Neurosci Abstr 24:659.

Blank T, Nijholt I, Teichert U, Kugler H, Behrsing H, Fienberg A, Greengard P, Spiess J (1997) The phosphoprotein DARPP-32 mediates cAMP-dependent potentiation of striatal $N$-methyl-D-aspartate responses. Proc Natl Acad Sci USA 94:14859-14864.

Brog JS, Salyapongse A, Deutch A, Zahm DS (1993) The pattern of afferent innervation of the core and shell in the "accumbens" part of the ventral striatum: immunohistochemical detection of retrogradely transported fluoro-gold. J Comp Neurol 338:255-278.

Calabresi P, Centonze D, Bernardi G (2000) Electrophysiology of dopamine in normal and denervated striatal neurons. Trends Neurosci [Suppl] 23:S48-S56.

Callaway CW, Hakan RL, Henriksen SJ (1991) Distribution of amygdala input to the nucleus accumbens septi: an electrophysiological investigation. J Neural Transm 83:215-225.

Cepeda C, Levine MS (1998) Dopamine and N-Methyl-D-Aspartate receptor interactions in the neostriatum. Dev Neurosci 20:1-18.

Chergui K, Lacey MG (1999) Modulation by dopamine $\mathrm{D}_{1}$-like receptors of synaptic transmission and $\mathrm{NMDA}$ receptors in rat nucleus accumbens is attenuated by the protein kinase C inhibitor Ro 32-0432. Neuropharmacology 38:223-231.

Chergui K, Suad-chagny MF, Gonon F (1994) Nonlinear relationship between impulse flow, dopamine release and dopamine elimination in the rat brain in vivo. Neuroscience 62:641-645.

DeFrance JF, Sikes RW, Chronister RB (1985) Dopamine action in the nucleus accumbens. J Neurophysiol 54:1568-1577.

Eichenbaum H (1996) Is the rodent hippocampus just for "place"? Curr Opin Neurobiol 6:187-195.

Feasy-Trugger KJ, ten Bruggencate G (1994) The NMDA receptor antagonist CPP suppresses long-term potentiation in the rat hippocampalaccumbens pathway in vivo. Eur J Neurosci 6:1247-1254.

Finch DM (1996) Neurophysiology of converging synaptic inputs from the rat prefrontal cortex, amygdala, midline thalamus, and hippocampal formation onto single neurons of the caudate/putamen and nucleus accumbens. Hippocampus 6:495-512.

Floresco SB, Phillips AG (1999) Dopamine and hippocampal input to the nucleus accumbens play an essential role in the search for food in an unpredictable environment. Psychobiology 27:227-286.

Floresco SB, Yang CR, Phillps AG, Blaha CD (1998) Basolateral amygdala stimulation evokes glutamate receptor-dependent dopamine efflux in the nucleus accumbens of the anesthetized rat. Eur J Neurosci 10:1241-1251.

Gonon F, Sundstrom L (1996) Excitatory effects of dopamine released by impulse flow in the rat nucleus accumbens in vivo. Neuroscience 75:13-18.

Groenewegen HJ, Berendse HW, Meredith GE, Haber SN, Voorn P, Wolters JG, Lohman AHM (1991) Functional anatomy of the ventral, limbic system innervated striatum. In: The mesolimbic dopamine system (Willner P, Scheel-Kruger J, eds), pp 19-59. New York: Wiley. 
Gurden H, Tassin J-P, Jay TM (1999) Integrity of the mesocortical dopaminergic system is necessary for complete expression of in vivo hippocampal-prefrontal cortex long-term potentiation. Neuroscience 94:1019-1027.

Gurden H, Takita M, Jay TM (2000) Essential role of D1 but not D2 receptors in the NMDA receptor-dependent long-term potentiation at hippocampal-prefrontal cortex synapses in vivo. J Neurosci 20:RC106.

Harvey J, Lacey MG (1997) A postsynaptic interaction between dopamine $\mathrm{D}_{1}$ and NMDA receptors promotes presynaptic inhibition in the rat nucleus accumbens via adenosine release. J Neurosci 17:5271-5280.

Hernández-López S, Bargas J, Surmeier DJ, Reyes A, Galarraga E (1997) $D_{1}$ receptor activation enhances evoked discharge in neostriatal medium spiny neurons by modulating an L-type $\mathrm{Ca}^{2+}$ conductance. J Neurosci 17:3334-3342.

Hu X-T, White FJ (1994) Loss of D1/D2 dopamine receptor synergism following repeated administration of D1 or D2 selective antagonists: electrophysiological and behavioral studies. Synapse 17:43-61.

Ikemoto S, Panksepp J (1999) The role of nucleus accumbens dopamine in motivated behavior: a unifying interpretation with special reference to reward seeking. Brain Res Rev 31:6-41.

McDonald RJ, White NM (1993) A triple dissociation of memory systems: hippocampus, amygdala, and dorsal striatum. Behav Neurosci 107:3-22.

Meredith GE, Totterdell S (1999) Microcircuits in nucleus accumbens' shell and core involved in cognition and reward. Psychobiology 27:165-186.

Mogenson GJ, Brudzynski SM, Wu M, Yang CR, Yim CY (1993) From motivation to action: a review of dopaminergic regulation of limbic $\rightarrow$ nucleus accumbens $\rightarrow$ ventral pallidum $\rightarrow$ pedunculopontine nucleus circuitries involved with limbic-motor integration. In: Limbicmotor circuits and neuropsychiatry (Kalivas PW and Barnes CD, eds), pp 193-263. Boca Raton, FL: CRC.

Mulder AB, Hodenpijl MG, Lopes da Silva FH (1998). Electrophysiology of the hippocampal and amygdaloid projections to the nucleus accumbens of the rat: convergence, segregation, and interaction of inputs. J Neurosci 18:5095-5102.

Nadel L (1992) Multiple memory systems: what and why. J Cogn Neurosci 4:179-188.

Nauta WJH, Smith GP, Faul RLM, Domesick VB (1978) Efferent connections and nigral afferents of the nucleus accumbens septi in the rat. Neuroscience 3:385-401.

Nestler EJ (1994) Hard target: Understanding dopaminergic neurotransmission. Cell 79:923-926.

Nicola SA, Malenka RC (1997) Dopamine depresses excitatory and inhibitory synaptic transmission by distinct mechanisms in the nucleus accumbens. J Neurosci 17:5697-5710.

Nicola SA, Kombian SB, Malenka RC (1996) Psychostimulants depress excitatory synaptic transmission in the nucleus accumbens via presynaptic $\mathrm{D}_{1}$-like dopamine receptors. J Neurosci 16:1591-1604.

Nicola SM, Surmeier DJ, Malenka RC (2000) Dopaminergic modulation of the neuronal excitability in the striatum and nucleus accumbens. Annu Rev Neurosci 23:185-215.

O’Donnell P, Grace AA (1995) Synaptic interactions among excitatory afferents to nucleus accumbens neurons: hippocampal gating of prefrontal cortical input. J Neurosci 15:3622-3639.

Oades RD (1985) The role of noradrenaline in tuning and dopamine in switching between signals in the CNS. Neurosci Biobehav Rev 9:261-282.

Paxinos G, Watson C (1997) The rat brain in stereotaxic coordinates, Ed 3. San Diego: Academic.

Pennartz CMA, Dolleman-vender Weel MJ, Kitai ST, Lopes Da Silva FH (1991) Presynaptic dopamine $D_{1}$ receptors attenuate excitatory and inhibitory inputs to the shell region of the rat nucleus accumbens studied in vitro. J Neurophysiol 67:1325-1333.

Pennartz CMA, Ameerun RF, Groenewegen HJ, Lopes Da Silva FH (1993) Synaptic plasticity in an in vitro slice preparation of the rat nucleus accumbens. Eur J Neurosci 5:107-117.

Pennartz CMA, Groenewegen HJ, Lopes Da Silva FH (1994) The nucleus accumbens as a complex of functionally distinct neuronal ensembles: an integration of behavioural, electrophysiological and anatomical data. Prog Neurobiol 42:719-761.

Redgrave P, Prescott TJ, Gurney K (1999) Is the short-latency dopamine response too short to signal reward error? Trends Neurosci 22:146-151.

Robbins TW, Everitt BJ (1996) Neurobehavioral mechanisms of reward and motivation. Curr Opin Neurobiol 6:228-236.

Salamone JD, Cousins MS, Bucher S (1997) Behavioral functions of nucleus accumbens dopamine: empirical and conceptual problems with the anhedonia hypothesis. Neurosci Biobehav Rev 21:341-359.

Schultz W (1998) Predictive reward signal of dopamine neurons. J Neurophysiol 80:1-27.

Sherry DF, Schacter DL (1987) The evolution of multiple memory systems. Psychol Rev 94:439-454.

Surmeier DJ, Kitai ST (1993) D1 and D2 dopamine receptor modulation of sodium and potassium currents in rat neostriatal neurons. Prog Brain Res 99:309-324.

Taepavarapruk P, Floresco SB, Phillips AG (2000) Hyperlocomotion and increased dopamine efflux in the nucleus accumbens evoked by electrical stimulation of the ventral subiculum: role of ionotropic glutamate and dopamine $\mathrm{D}_{1}$ receptors. Psychopharmacology 151:242-251.

Van de Bos R, Charria Ortiz GA, Bergmans AC, Cools AR (1991) Evidence that dopamine in the nucleus accumbens is involved in the ability of rats to switch to cue-directed behaviors. Behav Brain Res 42:107-114.

Voorn P, Jorristsma-Byhan, Van Dijk C, Buijs RM (1986) The dopaminergic innervation of the ventral striatum in the rat: a light and electron microscopic study with antibodies against dopamine. J Comp Neurol 251:84-96.

White FJ, Wang RY (1986) Electrophysiological evidence for the existence of both D-1 and D-2 dopamine receptors in the rat nucleus accumbens. J Neurosci 6:274-280.

Wickens JR, Begg AJ, Arbuthnott GW (1996) Dopamine reverses the depression of rat corticostriatal synapses which normally follows highfrequency stimulation of cortex in vitro. Neuroscience 70:1-5.

Yang CR, Mogenson GJ (1984) Electrophysiological responses of neurones in the nucleus accumbens to hippocampal stimulation and the attenuation of excitatory responses by the mesolimbic dopaminergic system. Brain Res 324:69-84.

Yang CR, Mogenson GJ (1986) Dopamine enhances terminal excitability of hippocampal-accumbens neurons via $\mathrm{D}_{2}$ receptor: role of dopamine in presynaptic inhibition. J Neurosci 6:2470-2478.

Yim CY, Mogenson GJ (1986) Neuromodulatory action of dopamine in the nucleus accumbens: an in vivo intracellular study. Neuroscience 26:403-415. 